\title{
DIAGNOSTIC ACCURACY OF ULTRASONOGRAPHY IN COMPARISON WITH COMPUTED TOMOGRAPHY IN DIAGNOSING ACUTE APPENDICITIS
}

\author{
Krishna Kumar Rama Krishnan', Venugopal Kodumur², N. Parthiban ${ }^{3}$
}

${ }_{1}^{1}$ Associate Professor, Department of Radiology, Aarupadai Veedu Medical College and Hospital, Pondicherry.

${ }^{2}$ Assistant Professor, Department of Radiology, Aarupadai Veedu Medical College and Hospital, Pondicherry.

${ }^{3}$ Assistant Professor, Department of Surgery, Aarupadai Veedu Medical College and Hospital, Pondicherry.

\section{ABSTRACT}

\section{BACKGROUND}

Studies regarding accuracy of Ultrasonography and Computed Tomography for diagnosis of appendicitis is not frequently done after the advancement in ultrasonography instrumentation. Imaging studies evolves rapidly due to advancement in technology. It is mandatory to update imaging methods for various pathologies.

Aims and Objectives- To assess and compare accuracy of Ultrasonography and Computed Tomography to diagnose acute appendicitis in patients with suspected acute appendicitis.

\section{MATERIALS AND METHODS}

Study Type- Descriptive study for diagnostic accuracy. Between January 2014 and January 2016, 400 patients who presented to emergency department with high clinical suspicion of appendicitis were evaluated with Ultrasonography and Computed Tomography. Computed Tomography examinations were performed with a sixteen-slice helical CT scanner (GE, Brivo, 385 series) by means of a rapid thin-scanning technique. For the Ultrasonography examinations, we used 5 to $11 \mathrm{MHz}$ linear array, 3 to $6 \mathrm{MHz}$ curved array (GE-Voluson S6). Curved array transducers were used in obese patients to allow deeper penetration. Ultrasonography examinations were performed using the graded compression technique described by Puylaert.[1,2] The Computed Tomography and Ultrasonography examinations were evaluated separately within 1 hour by two radiologists who were unaware of the findings on the other examination. The surgeon was not informed about the radiologic diagnosis. The surgeon decides further management in these patients based on clinical and laboratory data. The diagnosis of acute appendicitis at surgery was established based on macroscopic findings. A macroscopically normal appendix at laparoscopy was left intact. A normal looking appendix at laparotomy by a split-muscle incision was excised. All excised appendix was microscopically analysed by histology using paraffin sections for final diagnosis of acute appendicitis. All data underwent statistical analysis using the McNemar test. The study protocol was approved by the hospital's ethical committee for human studies.

\section{RESULTS}

The sensitivity of Ultrasonography and Computed Tomography was 95\% and 93\% respectively, and the specificity was $82 \%$ and $75 \%$ respectively. The positive predictive value was $91 \%$ and $87 \%$ respectively, and the negative predictive value was $90 \%$ and $85 \%$ respectively. The accuracy of Ultrasonography was $91 \%$ and CT was $87 \%$ respectively. Based on the McNemar test results, the calculated 'p' value for sensitivity, specificity and accuracy was not less than 0.05 , which indicates that CT was not superior to Ultrasonography in the diagnosis of acute appendicitis. On comparing Z=1.43 it is less than the level of significance value, i.e. 1.96, therefore not significant which concludes that Computed Tomography is not superior to Ultrasonography for diagnosing acute appendicitis.

\section{CONCLUSION}

USG for the diagnosis of acute appendicitis has accuracy same as that of Computed Tomography. Wall pattern and wall thickness is better studied with USG. Further studies are needed to compare wall thickness and wall pattern by USG and CT to conclude which modality is better for diagnosing acute appendicitis.

\section{KEYWORDS}

Acute Appendicitis, Ultrasonography, Computed Tomography.

HOW TO CITE THIS ARTICLE: Krishnan KKR, Kodumur V, Parthiban N. Diagnostic accuracy of ultrasonography in comparison with computed tomography in diagnosing acute appendicitis. J. Evolution Med. Dent. Sci. 2018;7(16):2033-2037, DOI: $10.14260 /$ jemds/2018/457

'Financial or Other Competing Interest': None.

Submission 14-03-2018, Peer Review 02-04-2018,

Acceptance 05-04-2018, Published 16-04-2018.

Corresponding Author:

Dr. Venugopal Kodumur,

\#11, Priyadarshini Street, Moogambighai Nagar,

Reddiyarpalayam-605010,

Pondicherry, India.

E-mail: drkrishnar1980@gmail.com

DOI: $10.14260 /$ jemds $/ 2018 / 457$

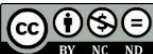

\section{BACKGROUND}

Studies regarding role of Ultrasonography and Computed Tomography for diagnosis of appendicitis is not frequently done after the advancement in ultrasonography instrumentation. Imaging studies evolve rapidly due to advancement in technology. It is mandatory to update imaging methods for various pathologies. This study was done to assess and compare accuracy of Ultrasonography and Computed Tomography to diagnose acute appendicitis in patients with suspected acute appendicitis. To evaluate advantages and disadvantages of Ultrasonography and 
Computed Tomography in diagnosing acute appendicitis after advancement in imaging studies at present.

\section{MATERIALS AND METHODS}

\section{Study Type}

Descriptive study for diagnostic accuracy.

A descriptive study for diagnostic accuracy was conducted between January 2015 and January 2017 to assess role of Ultrasonography and Computed Tomography for diagnosing appendicitis with suspected acute appendicitis. 578 patients who presented to Emergency Department with high clinical suspicion of acute appendicitis were evaluated with Ultrasonography and Computed Tomography. The patients were admitted to the hospital either for observation or for surgery. Unstable patients who needed to undergo emergency surgery were excluded from the study. In these cases, no imaging or either one of CT or USG was performed. Exclusion criteria were pregnancy and patients not willing to participate in the study. The radiologic procedures and purpose of the study were explained to the patients, and informed consent was obtained from each patient or from a patient's guardian in case of paediatric patients. The hospitalised patients underwent Computed Tomography and Ultrasonography examinations before undergoing surgery or during the first 24 hours of observation. The decision whether to operate or not was taken by the Surgeon based on the clinical symptoms and laboratory parameters.

Computed Tomography examinations were performed with a sixteen-slice multidetector helical CT scanner (GE, Brivo, 385 series) by means of a rapid thin-scanning technique. A single breath hold helical scan from the top of the D6 vertebral body to the pubic symphysis was obtained using 5 $\mathrm{mm}$ beam collimation and $10-\mathrm{mm} / \mathrm{sec}$ table speed (pitch of 1 , $120 \mathrm{kV}, 100$ to $160 \mathrm{~mA}$ ). Images were reconstructed and photographed at $1.25-\mathrm{mm}$ intervals using different soft-tissue window settings (Width, $400 \mathrm{H}$; level, $40 \mathrm{H}$ ). In patients younger than 10 years old, the tube current was $80 \mathrm{~mA}$. In patients between 10 and 15 years old, the tube current was $100 \mathrm{~mA}$. In patients 15 years or older, the tube current was 160 mA. No oral, rectal or IV contrast material was administered. CT scans were analysed both at a workstation and on hard copy. In this study, CT findings were interpreted as positive for acute appendicitis when an enlarged appendix $(\geq 6 \mathrm{~mm}$ in outer diameter) was identified (Fig. 1). Wall thickness of appendix and characterisation of wall was also done. CT findings were interpreted as negative, if the appendix was visualised with intraluminal air. An appendix less than $6 \mathrm{~mm}$ in outer diameter was also diagnosed as normal. If an appendix was not visualised and ancillary signs were or were not present, the findings were interpreted as negative.

For the Ultrasonography examinations, we used 5 to 11$\mathrm{MHz}$ linear array, 3 to 6-MHz curved array, (GE-Voluson S6). Curved array transducers were used in obese patients to allow deeper penetration. Ultrasonography examinations were performed using the graded compression technique described by Puylaert.[1,2] On Ultrasonography, the primary criterion to establish the diagnosis of acute appendicitis was direct visualisation of the inflamed appendix: a concentrically layered, small, sausage-like structure found at the point of tenderness. The classic appearance is a non-compressible blind ended tubular structure without peristalsis in RIF with maximum diameter of $6 \mathrm{~mm}$ or larger and echogenic incompressible peri-appendicular inflamed fat with or without an appendicolith (Fig. 2). The diagnostic criteria for negative findings on Ultrasonography were a compressible appendix, right lower quadrant without an enlarged appendix.

The Computed Tomography and Ultrasonography examinations were evaluated separately within 1 hour by two radiologists who were unaware of the findings on the other examination. The surgeon was not informed about the radiologic diagnosis. The surgeon decides further management in these patients. The diagnosis of acute appendicitis at surgery was established on the basis of macroscopic findings. A macroscopically normal appendix at laparoscopy was left intact. A normal-looking appendix at laparotomy by a split-muscle incision was excised. All excised appendix were microscopically analysed by histology using paraffin sections.

\section{Study Design}

Descriptive study for diagnostic accuracy.

\section{Statistical Method}

The sensitivity, specificity, positive predictive value and accuracy for CT and Ultrasonography in diagnosing acute appendicitis was calculated. McNemar test was applied for both tests to calculate ' $p$ ' value for sensitivity, specificity and accuracy.

\section{RESULTS}

Between January 2015 and January 2017, 578 patients with suspected acute appendicitis were hospitalised. Ninety patients were excluded. Twenty eight patients who were admitted for emergency appendectomy underwent immediate surgery. Twenty eight patients refused to take part in the study. The remaining 432 patients underwent both CT and Ultrasonography. In thirty two patients the radiologist considered it necessary to inform an independent surgeon about the radiologic findings before the operation, because of possible significant influence on the surgical and conservative management of the patient. Of the 432 patients considered for inclusion in the study, 400 patients fully followed the designed protocol. These 400 patients consisted of 221 females and 179 males, ranging in age from 3 to 92 years with fourteen patients younger than 12 years. Most patients 360 [88\%] underwent surgery immediately or within 24 hrs. of observation after imaging. Forty patients (12\%) were hospitalised for clinical observation after imaging. For this observation group the mean hospital stay was 3 days, ranging from 1 to 7 days. The latter group recovered without surgery during their stay in the hospital. The results of CT and Ultrasonography in these 27 patients are followed up. The median follow-up period was 13 months. All excised appendix was microscopically analysed by histology using paraffin sections for final diagnosis of acute appendicitis. All data underwent statistical analysis using the McNemar test.

At surgery 248 (69\%) of the 360 patients proved to have appendicitis and 112 patients (31\%) did not have appendicitis. In $58(16 \%)$ of these 360 patients, another diagnosis was 
made. In the other 54 patients without appendicitis (15\%), no diagnosis was made and the appendix was left intact.

The Ultrasonography results for the patients who underwent surgery are listed in Table 1. In 226 (91\%) of the 248 patients with appendicitis at surgery, the sonogram showed signs of acute appendicitis. The other 22 patients (9\%) appeared to have acute appendicitis at surgery, although the sonogram showed negative findings for appendicitis. In 101 (90\%) of the 112 patients without signs of appendicitis at surgery, Ultrasonography also did not reveal appendicitis. In $11(10 \%)$ of the 112 patients, the sonogram showed positive findings which was not found at surgery.

The CT results for the patients who underwent surgery are listed in Table 2. In 216 (87\%) of the 248 patients, CT showed acute appendicitis that was confirmed at surgery. The remaining 32 patients (16\%) appeared to have acute appendicitis at surgery, although the CT findings were negative.

In $96(86 \%)$ of the 112 patients with a macroscopically normal appendix at surgery, CT findings were negative for appendicitis. In the remaining 16 patients (14\%), CT findings were positive.

The sensitivity of CT and Ultrasonography was $95 \%$ and $93 \%$, and the specificity was $82 \%$ and $75 \%$ respectively. The positive predictive value was $91 \%$ and $87 \%$ and the negative predictive value was $90 \%$ and $85 \%$. The accuracy of CT is $88 \%$ and Ultrasonography was $91 \%$. On the basis of the McNemar test results, the calculated 'p' value for sensitivity, specificity and accuracy was not less than 0.05 , which indicates that CT was not superior to Ultrasonography in the diagnosis of acute appendicitis.

On comparing $\mathrm{Z}=1.43$ it is less than the level of significance value, i.e. 1.96. Therefore, not significant, which concludes that Computed tomography is not superior to Ultrasonography for diagnosing acute appendicitis.

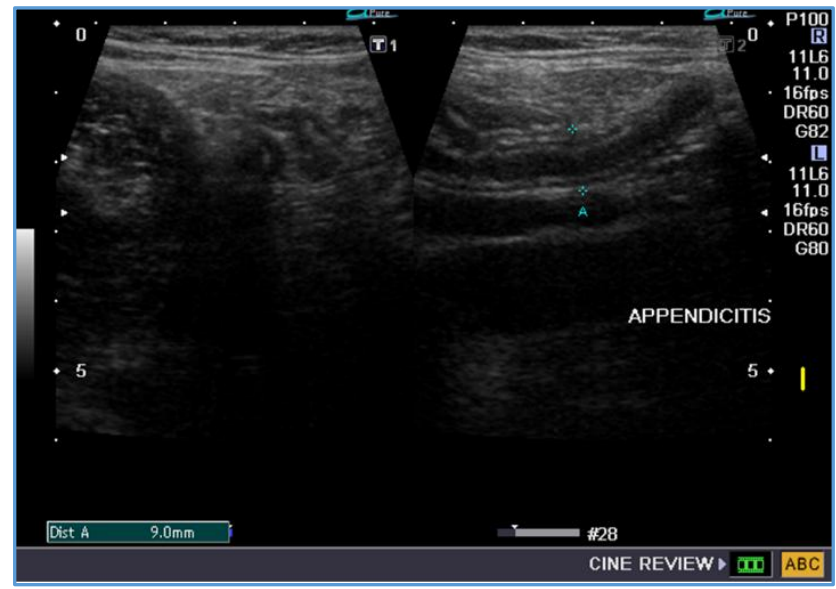

Figure 1. USG showing Appendicitis with Appendix Diameter of $9 \mathrm{~mm}$ (Between Calibers). Wall Pattern of Appendix is Well Visualised

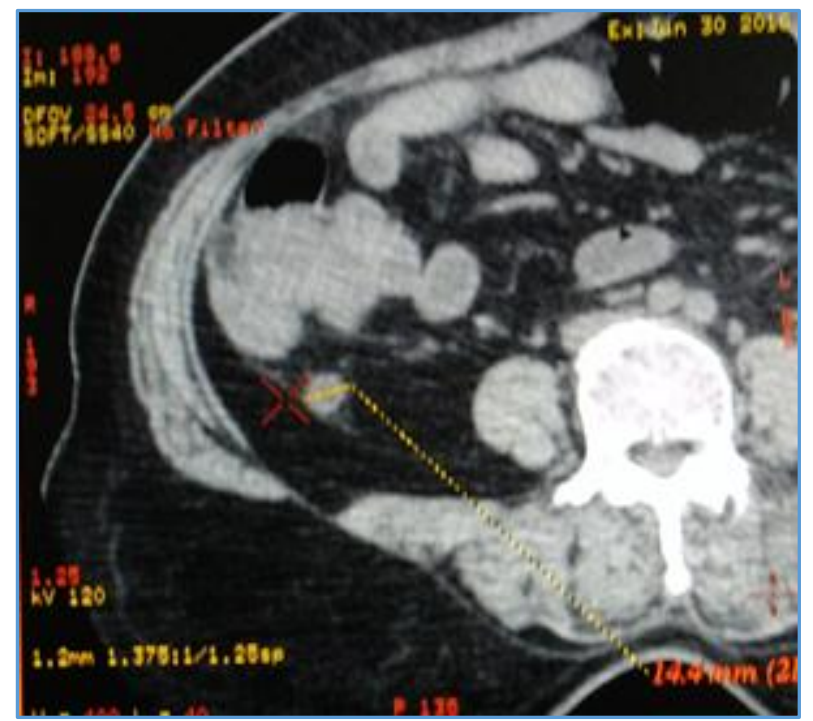

Figure 2. CT showing Appendicitis with Appendix Diameter of $14 \mathrm{~mm}$ (Medial to Cursor). Wall Pattern of Appendix is Not Visualised

\begin{tabular}{|c|c|c|c|}
\hline \multirow{2}{*}{$\begin{array}{l}\text { Surgery } \\
\text { Findings }\end{array}$} & \multicolumn{2}{|c|}{ Ultrasonography Findings } & \multirow{2}{*}{$\begin{array}{c}\text { No. of } \\
\text { Patients }\end{array}$} \\
\hline & Positive & Negative & \\
\hline Positive & 226 & 22 & 248 \\
\hline Negative & 11 & 101 & 112 \\
\hline Total & 237 & 123 & 360 \\
\hline \multicolumn{4}{|c|}{$\begin{array}{c}\text { Table 1. Correlation of Ultrasonography and Surgery } \\
\text { Findings for Diagnosis of Acute Appendicitis in } 360 \\
\text { Patients }\end{array}$} \\
\hline
\end{tabular}

\begin{tabular}{|c|c|c|c|}
\hline \multirow{2}{*}{$\begin{array}{c}\text { Surgery } \\
\text { Findings }\end{array}$} & \multicolumn{2}{|c|}{$\begin{array}{c}\text { Computed Tomography } \\
\text { Findings }\end{array}$} & $\begin{array}{c}\text { No. of } \\
\text { Patients }\end{array}$ \\
\cline { 2 - 3 } & Positive & Negative & \\
\hline Positive & 216 & 32 & 248 \\
\hline Negative & 16 & 96 & 112 \\
\hline Total & $\mathbf{2 3 2}$ & $\mathbf{1 2 8}$ & $\mathbf{3 6 0}$ \\
\hline Table 2. Correlation of Computed Tomography and \\
Surgery Findings for Diagnosis of Acute Appendicitis in \\
360 Patients
\end{tabular}

\section{DISCUSSION}

Graded compression Ultrasonography of the right lower quadrant has gained increasing acknowledgement in establishing the diagnosis of acute appendicitis with sensitivities ranging from $77 \%$ to $89 \%$ and specificities ranging from $94 \%$ to $96 \% .[1,3-16]$ The sensitivity and specificity of Ultrasonography found in our study is close to these results.

Wall pattern and wall thickness are better assessed with Ultrasonography, which adds to the diagnostic efficiency of ultrasonography in acute appendicitis. But further studies are needed to confirm this.

Wall pattern is better seen in USG. CT is not efficient in evaluating wall pattern, because of uniform water density for soft tissue. Loss of wall pattern by Ultrasonography in acute appendicitis may denote perforation, gangrene or severe inflammation with possible adhesion. In our study, perforation of appendix is better assessed with USG than CT. Ultrasonography is relatively inexpensive, rapid, non-invasive, and requires no patient preparation or contrast material administration. 
Unfortunately, graded compression Ultrasonography is operator-dependent and requires a high level of skill and expertise. Ultrasonography is also a dynamic investigation, and photographs of sonographic images cannot be reliably reevaluated. Obese patients and patients with a retrocaecal appendix or with severe abdominal pain are difficult to examine using Ultrasonography.[1,17] A radiologist in this study also indicated that these patient-related factors limited the diagnostic capability of Ultrasonography.

Some studies reported that CT is an accurate way of imaging acute appendicitis.[1,2,18-25] CT is readily available, is supposed to be operator independent and is relatively easy to perform and has results that are easy to interpret. Helical CT has reported sensitivities of $90 \%-100 \%$, specificities of 91 $99 \%$, accuracies of $94 \%$ - 98\%, positive predictive values of $92 \%$ - 98\%, and negative predictive values of $95 \%-100 \% .[1,26-$ 31,10-17] These studies are done in the period of 1990 to 2002, where USG instrumentation is not well evolved. With modern instrumentation, USG resolution is much improved and overcame much of the problems stated in those studies.

In our study $16(14 \%)$ of the 112 patients were found to have a normal appendix at surgery, but the CT findings were positive for appendicitis. Possible explanations for falsepositive CT results are mild appendicitis, resolved appendicitis or a reactive enlarged appendix caused by mesenteric lymphadenitis. $32(13 \%)$ of the 248 patients had acute appendicitis at surgery, although the CT findings were negative. These false-negative CT results may be also explained by the fact that less soft tissue temporal resolution and unable to determine wall pattern of appendix. In few patients, an alternative diagnosis was found at surgery. The cases of diverticulitis, Crohn's disease, cholecystitis and caecal tumours were detected at both CT and Ultrasonography. Of the gynaecologic diagnoses, the adnexal teratoma, the epidermoid cyst and most of the ovarian cysts were seen both on CT and on Ultrasonography. A limitation of this study may be that the radiologists were forced to state whether appendicitis was acute. There was no room for indeterminate answers. We believe that further prospective studies are needed to offer a diagnostic pathway in which Ultrasonography, CT and observation can be valuable tools in managing acute appendicitis.

Advantage of USG over CT are high soft tissue contrast, evaluation of wall pattern and wall thickness is better with USG than CT, easy to perform, readily available and cost effective.

\section{Disadvantage of USG over CT-}

1. Operator dependent, needs considerable expertise.

2. Resolution may be poor or appendix may not be visualised in case of overlapping bowel gas, tense abdomen and retroperitoneal appendix.

\section{Advantage of CT over USG-}

1. Reproducibility, images can be reviewed later.

2. Can be done in patient with severe abdominal pain and excessive gaseous prominence in abdomen.

\section{Disadvantage of CT over USG-}

1. Not readily available in all level of hospitals.

2. Wall pattern and wall thickness not reliable, evaluated with CT.

\section{CONCLUSION}

USG for the diagnosis of acute appendicitis has accuracy same as that of Computed Tomography. As the accuracy of CT is almost same as Ultrasound, in our view Ultrasound is the preferred modality to CT because Ultrasound is easily available and is an inexpensive modality and does not need any ionising radiation or intravenous contrast as in CT.

\section{Strength and Limitation}

Limitation- Wall pattern and wall thickness are better studied with USG. Further studies are needed to compare wall thickness and wall pattern by USG and CT to conclude which modality is better for diagnosing acute appendicitis.

\section{REFERENCES}

[1] Puylaert JB, Rutgers PH, Lalisang RI, et al. A prospective study of Ultrasonography in the diagnosis of appendicitis. N Engl J Med 1987;317(11):666-9.

[2] Puylaert JB. Acute appendicitis: US evaluation using graded compression. Radiology 1986;158(2):355-60.

[3] Stroman DL, Bayouth CV, Kuhn JA, et al. The role of computed tomography in the diagnosis of acute appendicitis. Am J Surg 1999;178(6):485-9.

[4] Abu-Yousef MM, Bleicher JJ, Maher JW, et al. Highresolution sonography of acute appendicitis. AJR Am J Roentgenol 1987;149(1):53-8.

[5] Franke C, Bohner H, Yang Q, et al. Ultrasonography for diagnosis of acute appendicitis: results of a prospective multicenter trial. Acute Abdominal Pain Study Group. World J Surg 1999;23(2):141-6.

[6] Balthazar E, Birnbaum B, Yee J, et al. Acute appendicitis: CT and US correlation in 100 patients. Radiology 1994;190(1):31-5.

[7] Wilson EB, Cole JC, Nipper ML, et al. Computed tomography and Ultrasonography in the diagnosis of appendicitis. When are they indicated? Arch Surg 2001;136(6):670-5.

[8] Pickuth D, Heywang-Kobrunner SH, Spielmann RP. Suspected acute appendicitis: is Ultrasonography or computed tomography the preferred imaging technique? Eur J Surg 2000;166(4):315-9.

[9] Horton M, Counter SF, Florence MG, et al. A prospective trial of computed tomography and Ultrasonography for diagnosing appendicitis in the atypical patient. Am J Surg 2000;179(5):379-81.

[10] Wise SW, Labuski MR, Kasales CJ, et al. Comparative assessment of CT and sonographic techniques for appendiceal imaging. Am J Roentgenol 2001;176(4):933-41.

[11] Sivit CJ, Applegate KE, Stallion A, et al. Imaging evaluation of suspected appendicitis in a pediatric population: effectiveness of Ultrasonography versus CT. Am J Roentgenol 2000;175(4):977-80.

[12] Kaiser S, Frenckner B, Jorulf HK. Suspected appendicitis in children: US and CT-a prospective randomized study. Radiology 2002;223(3):633-8.

[13] Lowe LH, Penney MW, Stein SM, et al. Unenhanced limited CT of the abdomen in the diagnosis of appendicitis in children: comparison with sonography. Am J Roentgenol 2001;176(1):315. 
[14] Birnbaum BA, Jeffrey RB. CT and sonographic evaluation of acute right lower quadrant abdominal pain. Am J Roentgenol 1998;170(2):361-71.

[15] Styrud J, Josephson T, Eriksson S. Reducing negative appendectomy: evaluation of Ultrasonography and computer tomography in acute appendicitis. Int J Qual Health Care 2000;12(1):65-8.

[16] Borushok KF, Jeffrey RB, Laing FC, et al. Sonographic diagnosis of perforation in patients with acute appendicitis. Am J Roentgenol 1990;154(2):275-8.

[17] Birnbaum BA, Wilson SR. Appendicitis at the millennium. Radiology 2000;215(2):337-48.

[18] Lane MJ, Katz DS, Ross BA, et al. Unenhanced helical CT for suspected acute appendicitis. Am J Roentgenol 1997;168(2):405-9.

[19] Balthazar EJ, Megibow AJ, Siegel SE, et al. Appendicitis: prospective evaluation with high-resolution CT. Radiology 1991;180(1):21-4.

[20] Lane MJ, Liu DM, Huynh MD, et al. Suspected acute appendicitis: non-enhanced helical CT in 300 consecutive patients. Radiology 1999;213(2):341-6.

[21] Pickuth D, Spielmann RP. Unenhanced spiral CT for evaluating acute appendicitis in daily routine: a prospective study. Hepatogastroenterology 2001;48(37):140-2.

[22] Raman SS, Lu DS, Kadell BM, et al. Accuracy of nonfocused helical CT for the diagnosis of acute appendicitis: a 5-year review. Am J Roentgenol 2002;178(6):1319-25.

[23] Peck J, Peck A, Peck C, et al. The clinical role of noncontrast helical computed tomography in the diagnosis of acute appendicitis. Am J Surg 2000;180(2):133-6.

[24] Wijetunga R, Tan BS, Rouse JC, et al. Diagnostic accuracy of focused appendiceal CT in clinically equivocal cases of acute appendicitis. Radiology 2001;221(3):747-53.
[25] Rao PM, Rhea JT, Novelline RA. Sensitivity and specificity of the individual CT signs of appendicitis: experience with 200 helical appendiceal CT examinations. J Comput Assist Tomogr 1997;21(5):686-92.

[26] Jacobs JE, Birnbaum BA, Macari M, et al. Acute appendicitis: comparison of helical CT diagnosis focused technique with oral contrast material versus non-focused technique with oral and intravenous contrast material. Radiology 2001;220(3):683-90.

[27] Rao PM, Rhea JT, Novelline RA, et al. Helical CT combined with contrast material administered only through the colon for imaging of suspected appendicitis. Am J Roentgenol 1997;169(5):1275-80.

[28] Funaki B, Grosskreutz SR, Funaki CN. Using unenhanced helical CT with enteric contrast material for suspected appendicitis in patients treated at a community hospital. Am J Roentgenol 1998;171(4):997-1001.

[29] Rao PM, Rhea JT, Novelline RA, et al. Helical CT technique for the diagnosis of appendicitis: prospective evaluation of a focused appendix CT examination. Radiology 1997;202(1):139-44.

[30] Rao PM, Rhea JT, Novelline RA, et al. Effect of computed tomography of the appendix on treatment of patients and use of hospital resources. $N$ Engl J Med 1998;338(3):141-6.

[31] Malone AJ, Wolf CR, Malmed AS, et al. Diagnosis of acute appendicitis: value of unenhanced CT. Am J Roentgenol 1993;160(4):763-6. 